\title{
OPTIMAL SITTING AND SIZING OF CAPACITOR BANKS USING MULTI-OBJECTIVE GENETIC ALGORITHM
}

\author{
Adel A. Abou El-Ela \\ Faculty of Engineering, \\ Minoufiya University
}

\author{
Gamal E. M. Aly \\ Faculty of Engineering, \\ Tanta University
}

\author{
Abeer A. E. Shammah \\ South Delta Electricity \\ Distribution Company SDEDC
}

\begin{abstract}
This paper presents a proposed optimization procedure (POP) to find the optimal sitting and sizing of capacitor banks in order to reduce the power and energy losses, increase the available capacity of the feeders and improve the feeder voltage profile. This technique uses the voltage regulation index (VRI) and loading performance index (LPI) to find the optimal placement of capacitor banks in the radial distribution systems (RDS). The multi-objective Genetic algorithm (MOGA) is used as an optimization technique to achieve the multi-nonlinear inflected objective functions for optimal sitting and sizing of capacitor banks problem. These objective functions are: minimizing the cost of power losses, minimizing the cost of energy losses, minimizing of voltage deviation, minimizing the cost of capacitor banks and maximizing of the feeder power factor. These objective functions are achieved simultaneously, while many radial distribution system constraints are satisfied. Actual power distribution systems, as apart of Egyptian distribution network, are used to show the capability of the proposed technique to improve the feeder performance through optimally sitting and sizing of capacitor banks.

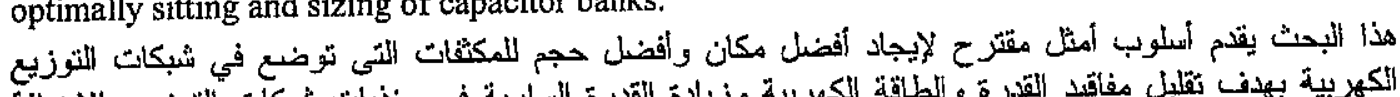

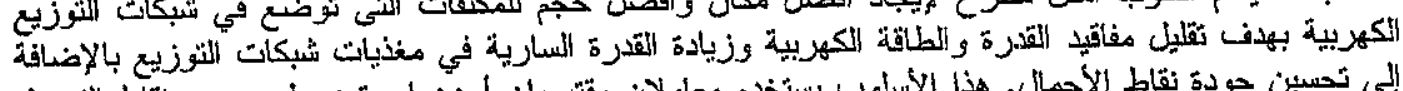

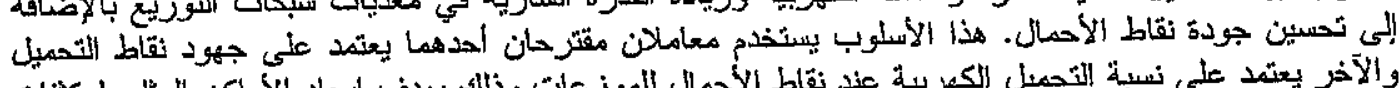

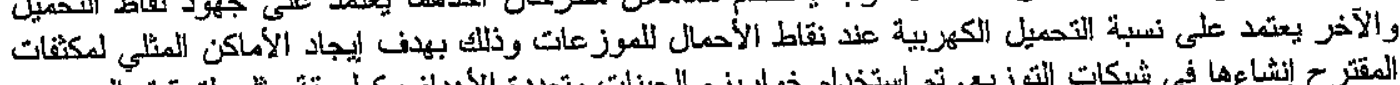

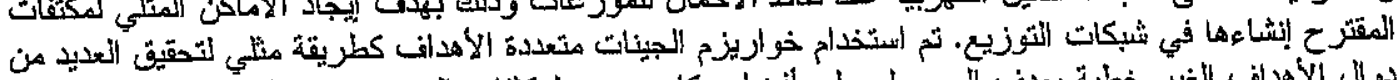

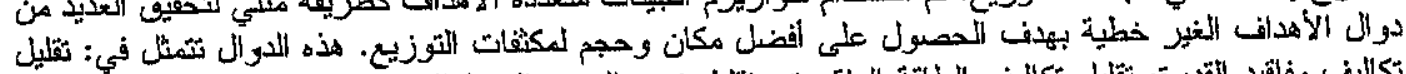

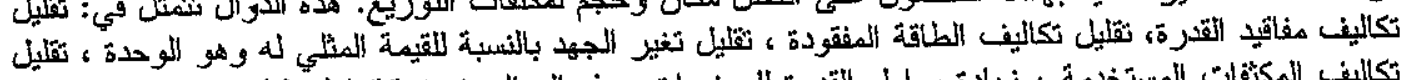

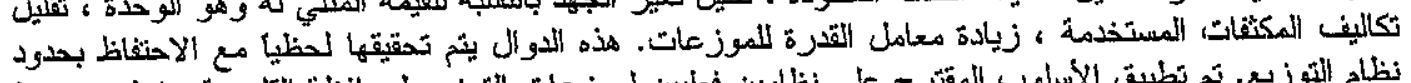

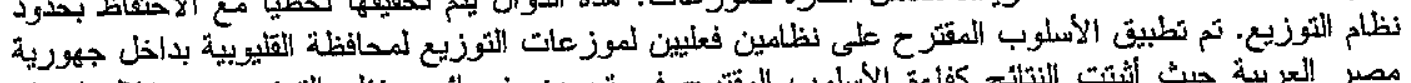

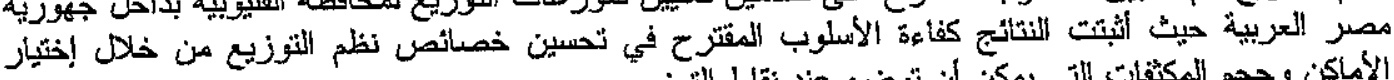

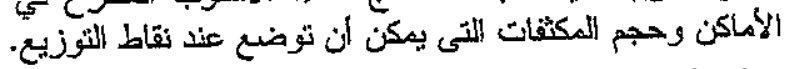

Keywords: Optimal placement of capacitor banks - performance indices - Multi-objective functions - Genetic Algorithms - Radial distribution systems.

\section{INTRODUCTION}

Capacitor banks are added to radial distribution systems for power factor correction, loss reduction, and voltage profile improvement. With these various objectives in mind and subject to operating constraints, optimal capacitor placement aims to determine capacitor sizes and locations. This problem has received considerable attention from researchers and utilities in the lost four decades. The losses can be reduced by adding shunt capacitors to supply part of reactive power demands. Reference [1] developed a procedure for optimizing the net momentary saving associated with the reduction of energy loss by placing fixed and switched capacitors. Non-linear programming (NLP) was applied to find the optimum location and rating of both fixed and switched capacitors to be placed on distribution systems. Early approaches were based on heuristic techniques applied to relaxed versions of the problem (some of the more difficult constraints were propped). More rigorous approaches were suggested as illustrated by Grainger [1] and [2]. In the 90 's, combinatorial algorithms were introduced as a means of solving the capacitor placement problem. The genetic algorithms $(\mathrm{GA})$ in [3-6] presented an integer-coded $\mathrm{GA}$ (IGA) for solving the full reactive-power compensation planning problem that does not violate any system or operational constraint. The cost minimization is targeted only for the base case, as a system has to be secure in all cases. In [4], a number of modifications have been presented to improve the performance of the simple genetic algorithm in 
solving the capacitor placement problem. Reference [5] presented a practical solution technique to improve the feeder performance through optimallyplaced capacitors. This is accomplished using GA which are search and optimization techniques that are suitable to solve the non-linear optimization problems also Dynamic programming (DP) has also been applied for the same problem. In [6], the optimal locations was determined by sensitivity analysis, and only the capacitor-sizing problem solved by GA. Tabu search algorithms in [7] and a hybrid algorithms based tabu search, including heuristic features (Sensitivity analysis) [8] were presented. Heuristic technique was applied by some researchers to find the optimal size and location of capacitors [8]. Fuzzy set theory based multi-stage optimization was developed to reach an optimal size, location and commitment schedule of capacitor banks on a yearly based operation [9].

In general, a distribution system is fed at only one point and the structure of the network is mainly radial. For such systems, all active power demands and losses must be supplied by the source at the main node. However, addition of shunt capacitors can generate reactive power and therefore it is not necessary to supply all reactive power demands and losses by the source. Thus, there is a provision to minimize the losses associated with the reactive power flows through the branches. Probabilistic search techniques, such as simulated annealing and genetic algorithms, can efficiently be applied to solve such non-differentiable combinatorial optimization problems.

In this paper, performance index according to voltage regulation percentage where the voltages along the feeder are remained within upper and lower limits, typically within $\pm 5 \%$ of the rated feeder voltage, prior to or after the addition of capacitors on the feeder. Performance index according to the loading percentage is used to find the optimal locations of the capacitor banks in the RDS. A POP is employed to determine the optimal sizing and sitting of the capacitor banks to improve the performance of actual two feeders which are a parts of Egypt distribution system. The feeders consist of a main line, number of laterals which may be comprised of several segments of different lengths and number of nodes. The feeder serves a mixture of residential and commercial loads.

\section{PROBLEM FORMULATION}

The optimal allocation of the reactive sources reduces the system losses due to reduction of current in the distribution feeders. Generally, the location and sizing of shunt capacitors is formulated as an optimum problem to minimize the cost of capacitor banks, cost of feeder active power losses, cost of energy losses and voltage deviation related to flat voltage as well as to maximize the feeder power factor subjected to the operating system constraints. The capacitor banks are equal in size and are composed of an integral number of identical units of standard size. So, a capacitor bank size obtained from the POP's solution is approximated to a nearest standard size:

\subsection{Objective Function}

The objective function includes minimization of active power losses cost, minimization of energy losses cost, minimization of voltage deviation related to the flat voltage (1.0 per unit) and minimization of capacitor banks cost and maximization of the feeder power factor, while the operating constraints are satisfied:

\section{a. Minimization of active power losses cost}

This objective function aims to minimize the active power losses cost as:

$$
\operatorname{Min} F_{1}=\operatorname{Min} \sum_{i=1}^{n} 3 T 10^{-3} I_{i}^{2} R_{i}(L L F)
$$

where, $n$ is the total number of branches, $I_{i}$ is the load current flow in branch $i, R_{i}$ is the resistance of branch $i, T$ is the number of operating houts per year and $L L F$ is the loss of load factor which is a function of load factor $(L F)$ as [10]:

$$
L L F=A(L F)^{2}+B(L F) \text { where } A+B=1
$$

Then, the cost of the active power losses can be : expressed as:

$$
\begin{aligned}
& M i n C_{p}=\operatorname{MinK} K_{p} \\
&=\operatorname{Min} 3 K_{p} T 10^{-3} \sum_{i=n}^{n} I_{l}^{2} R_{l}(L L F) \\
& \text { L.E/year }
\end{aligned} \mid
$$

Where, $K_{p}$ is the cost of the active power losses

\section{b. Minimization of energy losses cost}

The total energy loss is to be calculated on the basis of present worth cost for the period of conductor, assuming the life time is $D$ years for a discount rate of annual percentage equals $r$. Therefore, the energy loss costs can be expressed as [10]:

$$
M i n F_{2}=\sum_{i=1}^{n} 3 T 10^{-3} I^{2}{ }_{i} R_{i}(L L F) h \sum_{d=1}^{D}\left(1 /(1+r)^{d}\right)
$$

Where, $h$ is the cost of energy per kWh.

\section{c. Minimization of voltage deviation}

The voltage deviation with respect to the flat voltage must be minimized, so that the regulation factor at load node in the distribution system can be modified. This objective function can be expressed as:

$$
\operatorname{Min} F_{3}=\sum_{j=1}^{N}\left(V_{j}-V^{s p}\right)
$$


Where, $V_{j}$ is the voltage magnitude at node $j, V^{s p}$ is specified voltage (1.0 per unit) and $N$ is the total number of load nodes.

\section{d. Minimization of capacitor banks cost}

Any discussion on the use of capacitor should involve some considerations of the economic tradeoffs associated with their installation. The capital cost of the capacitor bank $\mathrm{C}_{\mathrm{c}}$ in a single installation bears a linear relationship to the capacitor current. This involves fixed and variable cost for the capacitor. The fixed cost component represents the installation and labor cost and the cost of miscellaneous hardware, which includes the support structure, fuse cutout, and lightning arrestor, while the variable cost depends on its kVA capacity.

$$
\operatorname{Min} F_{4}=\operatorname{Min} C_{c}=\sum_{j=1}^{n} e \cdot i_{c j}+a . d
$$

\section{Where}

$i_{c j}$ is the capacitive current flow in segment,

$e$ is the variable cost component of a capacitor bank,

$d \quad$ is the fixed cost component of a capacitor bank.

$$
i_{c j}=I_{c j-}-I_{c j} \quad j=1,2,3, \ldots \ldots . h
$$

The factor "a" is a decision factor depends whether there is a capacitor bank to be used at this node or not.

$$
\begin{array}{ll}
a=1 & i_{c}>0 \\
a=0 & i_{c}=0
\end{array}
$$

If $\mathrm{r}$ is the annual discount rate during the life period of the capacitor, the general cost model of the capacitor bank can be written as:

$C_{C}=\sum_{j=1}^{n} \sum_{k=1}^{N} \frac{\left(e . i_{c j}+a . d\right)}{(1+r)^{k}}$

\section{e. Maximization of feeder power factor}

$$
\operatorname{Max} F_{5}=\cos \phi
$$

Where,

$\cos \phi=\cos \left[\tan ^{-1}\left(\phi_{1}-\phi_{2}\right)\right]=\cos \left[\tan ^{-1} \frac{Q}{P}\right]$

$\phi_{1}$ is the voltage phase angle before using of capacitor bank.

$\phi_{2}$ is the voltage phase angle after using of capacitor bank.

\subsection{System Constraints}

The minimization of objective functions $\left(F_{1}-F_{5}\right)$ may lead to violated in any RDS constraint.

\section{a) Voltage level constraints}

The voltage level at the consumer, in the RDS, is the main constraint. The voltage drop in the distribution feeder depends on the choice of its cross- section area, loading level, power factor and circuit operating voltage. However the small value of feeder voltage drop leads to high conductor size and consequently lower system losses. The voltage magnitude at each node must be maintained within its limits as:

$$
V_{j}^{\min } \leq V_{j} \leq V_{j}^{\max } \quad j=1, \ldots, N
$$

Where, $V_{j}^{\min }$ and $V_{j}^{\max }$ are the minimum and maximum voltage magnitude at node $j$.

\section{b) Real and reactive power generation.constraints}

Real and reactive power generation from any device must be within specified limits as:

$$
\begin{aligned}
& P_{i}^{\min } \leq P_{i} \leq P_{i}^{\max } \\
& Q_{i}^{\min } \leq Q_{i} \leq Q_{i}^{\max }
\end{aligned}
$$

Where, $P_{i}$ and $Q_{i}$ are the real and reactive power generation at node $i$.

\section{c) Real and reactive power balance}

The real and reactive power balance at each node must be within acceptable tolerances as:

$$
\begin{aligned}
& \sum_{j=1}^{N} P_{j b}=L_{p b}+\delta P_{b} \\
& \sum_{j=1}^{N} Q_{j b}=L_{q b}+\delta Q_{b}
\end{aligned}
$$

\section{Where,}

$P_{j b}$ is the real power flow from node $j$ to node $b$.

$L_{p b}$ is the real power demand at node $b$.

$\delta P_{b}$ is the real power imbalance tolerance at node $b$.

$Q_{j h}$ is the reactive power flow from node $j$ to node $b$.

$L_{q b}$ is the reactive power demand at node $b$.

$\delta Q_{b}$ is the reactive power imbalance tolerance at $b$.

\section{d) The power factor constraint}

The power factor (PF) correction due to placing a capacitor bank on a radial distribution feeder must be within specified limits as:

$$
0.95 \leq P F \leq 1.0
$$

\section{e) The number of capacitor banks constraint}

The number of capacitor banks can be specified according to the following expression:

$$
\sum_{i=1}^{m} Q_{c} \leq Q_{\text {total }}
$$

Where, $Q_{c}$ is the $\mathrm{kVAr}$ obtained from the capacitor bank, $Q_{\text {foral }}$ is the total reactive power flows in the feeder and $m$ is the number of capacitor banks.

\section{GENETIC ALGORITHM FOR OPTIMAL CAPACITOR PLACEMENT}

Genetic algorithm (GA) uses a biological analogy to evolve a population of search - space 
Adel A. Abou El-Ela, Gamal E. M. Aly, and Abeer A. E. Shammah, "Optimal Sitting and Sizing of ...... "

points toward an optimal solution, and has been applied to several disciplines in engineering and the sciences.

The algorithm is attractive due to its ease of implementation, its lack of differentiability requirements on the objective function, and, its ability to find globally optimal solutions. These properties allow optimization of a practical formulation of the capacitor placement problem, which includes the discrete nature of capacitor installations. The composition of the genetic string and the fitness function selected here are described below along with the capacitor placement algorithm. However, GA is one kind of random search the capacitor sizes selected by different genetic strings. The capacitor sizes at different nodes are therefore modified to make the feasible solution of that problem [10].

\subsection{The Genetic Chromosome}

Integer vectors representation was used successfully in optimization problems in which the solution is a permutation, such as in optimal capacitor placement problem. This is the reason to choose precisely, a vector of integers as representation method. Each gene of the chromosome is an integer representing the node affected and the size of capacitors that will be added on this node. In this case, the representation by means of strings of bits was chosen. Each gene $j$ of the chromosome can store as 0 , which indicates absence of capacitors on the corresponding node or an integer different from $0(\leq$ $\mathrm{m})$ that indicates the number of added capacitors sizes that is added in the node $j$. Another restriction is imposed on the sum of all sizes performed on a certain vector population, i.e. the sum of all vector population, components does not exceed $\mathrm{k}$. Where, $\mathrm{k}$ is the compensation level represented by a chromosome may be too high, giving an infeasible solution. Such chromosome, if not modified properly, will increase the number of generations required to obtain a good solution. The compensation level is therefore modified for those chromosomes for which the total compensation level exceeds an upper limit.

\subsection{New Operators}

Many operators have been defined in the literature to cover a wide band of search space of the GAs [25, 26]. The first operator suggested in this paper is shuffling operator and the second is inversion operator which can be defined as follows:

\section{a) Shuffling Operator}

Shuffling selects one from born child and creates a new one. The simplest way to do this is to choose randomly two shuffling points and everything between these points randomly selected again, as shown in Fig. 1. Shuffling can then look like as follows ( $\mid$ is the shuffling points):

\begin{tabular}{|c|c|c|}
\hline Child & 11011 & 001001 \\
\hline New Child & 11011 & 110000 \\
\hline
\end{tabular}

Fig. 1. The shuffling operator

\section{b) Inversion Operator}

Inversion selects one from born child and creates a new one. The simplest way to do this is to choose randomly two inversion points and all genes between these points are flipped, as shown in Fig. 2. Inversion can then look like as follows ( $\mid$ is the inversion points):

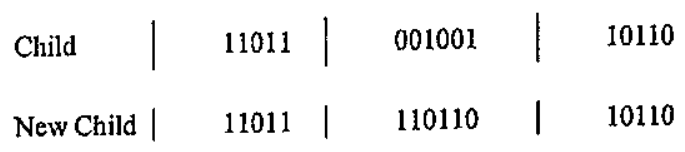

Fig. 2. The inversion operator

\subsection{Complete Capacitor Placement Algorithm}

The GA based capacitor placement algorithm consists of the following steps:

Step 1: Generate a population of genetic algorithm strings.

Step 2: Perform load flow corresponding to the capacitor setting of the chromosome.

Step 3: Determine the fitness value of each chromosome.

Step 4: Select two parent strings.

Step 5: Perform crossover to generate two children.

Step 6: Choose, randomly, one of the following operators:

*Mutation operator,

*Shuffling operator, or

* Inversion operator.

Step 7: If generation $=$ Maximum generation, stop; otherwise, generation $=$ generation $+1 ;$ go to step 2 .

\subsection{Fitness Objective Function}

The objective of the capacitor placement problem is to minimize the total cost of operation, including the cost of capacitors and the cost of energy losses as well as to maintain the node voltages within the specified limits.

GA search is guided by the fitness values of the chromosomes, and the goal of the search process is to minimize the fitness function value.

\section{PROPOSED PERFORMANCE INDICES}

The proposed performance indices can be applied, with respect to the node voltage and node load for normal conditions.

\subsection{Voltage Regulation Index (VRI)}

The specified values, of the voltages at all nodes, $V^{s p}$ is considered as (11kv) then; the proposed 
performance voltage index at each node can be calculated from:

$$
V R I \%=\frac{V^{s p}-V_{i}}{V^{s p}} * 100
$$

Where, $V_{i}$ is the voltage magnitude at normal condition at node $(i)$.

The node that has the largest $V R I \%$ will be indexed at the top of list and is considered as the most sensitive node (far from the flat voltage). This node is sensitive to violate its voltage limit due to any change in the configuration of the network or any change in the operating conditions. But, the node that has the smallest $V R I \%$ will be closed to the flat voltage and occupies the bottom of the list. This node is considered insensitive to any change in the network configuration or in the operating condition.

\subsection{Loading Performance Index (LPI)}

This index can be expressed for each distribution node $k$ as:

$$
L P I \%=\frac{L P_{t}-L P_{k}}{L P_{t}} * 100
$$

Where, $L P_{t}$ is the sum of loads in $(\mathrm{kw})$ at all nodes of the feeder, $P L_{k}$ is the actual load at node $\mathrm{k}$.

The smallest positive performance index value means that the node value is heavily loaded. The list will be filled with the overloaded nodes at the top, after that the heavily loaded nodes and then the other nodes according to their index.

\section{PROPOSED OPTIMIZATION PROCEDURE}

The optimal proposed procedure concerns with planning problem of finding the sitting and sizing of capacitor banks which is located at load nodes. These capacitor banks will be used to minimize power and energy losses, voltage deviation and respectively the corresponding cost of power and energy. However, these functions are often competing and conflicting objectives. Multi-objective optimization with such conflicting objective functions gives rise to sets of optinal solutions, instead of one optimal solution. The multi-objective optimization problem is carried out using the GA to achieve the fitness function as shown as in:

$$
\begin{array}{r}
\operatorname{Min} F=w_{1} F_{1}+w_{2} F_{2}+w_{3} F_{3} \\
+w_{4} F_{4}+w_{5} \cdot F_{5}
\end{array}
$$

Where, $\left(w_{l}-w_{s}\right)$ are weighting factors.

Since, there is no feasible solution when these objectives are minimized simultaneously, the priority goal programming (PGP) is used to optimize several objective functions. However the $w_{l}$ takes 1.0 while the other weighting factors $w_{2}-w_{5}$ take zero in order to minimize $F_{l}$ and so on to achieve other objective function separately. In other side, the weighting factors $w_{i} w_{5}$ take 1.0 to achieve all objective functions $\left(F_{I}-F_{S}\right)$, simultaneously.

The optimal sitting of these capacitors depends on the performance index of loading condition $(L P I)$ for each node of feeder, as shown in Equation (18). The point of feeder which has the smallest $L P I$ is considered as a sensitive point which needs to install a capacitor bank in order to modify the node voltage.

\section{APPLICATIONS}

\subsection{Cases study}

Two real cases study [11] are used to find the optimal sitting and sizing of capacitor banks in the RDS. These cases study are real parts of Egyptian distribution network which are related to Kalubyah Governorate. Figures 3 and 4 show the configuration of these distribution systems, respectively.

The cost of kWh is equal to 0.14 Egyptian pounds (LE), while the cost of $\mathrm{kW}$ is $60 \mathrm{LE}$ and the cost of capacitor unit is $11000 \mathrm{LE}$. The rate of each capacitor unit is $300 \mathrm{kVAr}$ and the number of units depends on the total reactive power flows in the feeder.

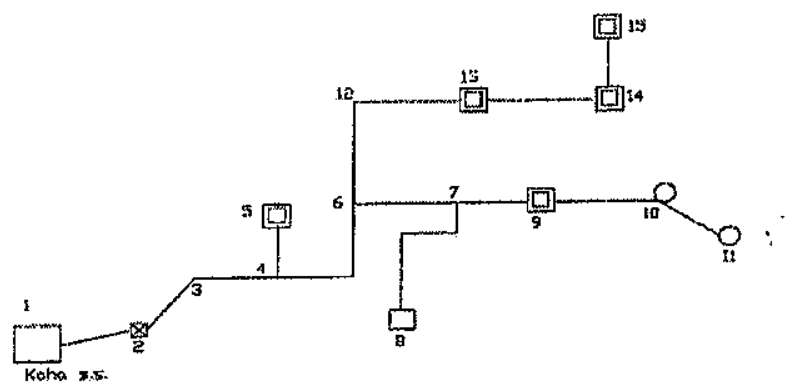

Fig. 3. First distributor case study

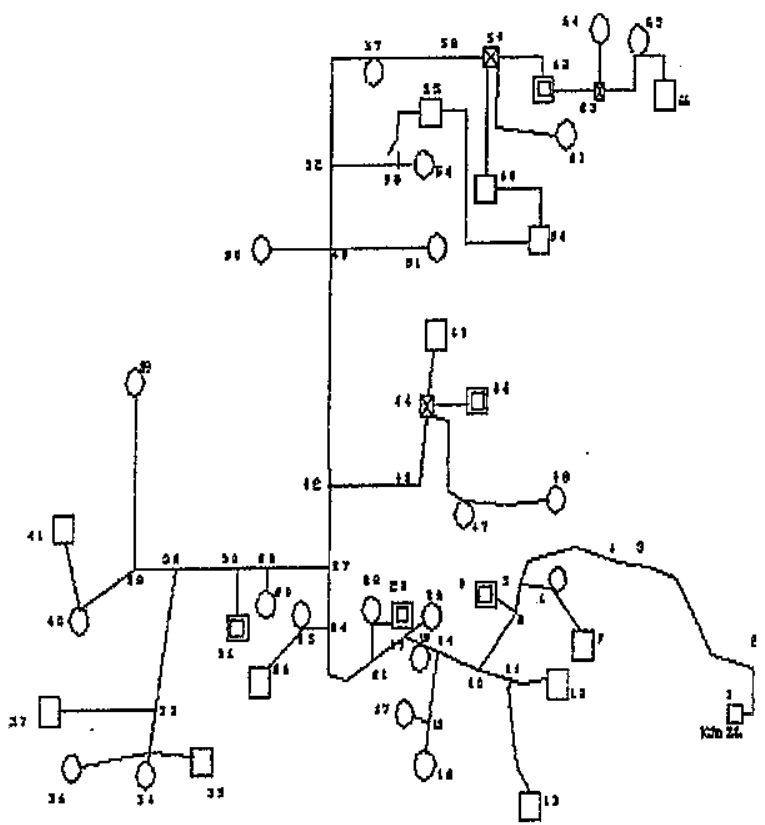

Fig. 4. Second distributor case study 


\subsection{Results and Comments}

The GA parameters which are used in this study are, Population size (pop.) $=80$, Number of populations $\left(\mathbf{N}_{\text {pop }}\right)=100$, Probability of crossover $\left(\mathrm{P}_{\mathrm{c}}\right)=50 \%$, Probability of mutation $\left(\mathrm{P}_{\mathrm{N}}\right)=5 \%$, Solution Precession $\left(\mathrm{P}_{\mathrm{r}}\right)=0.001$.

\subsubsection{First case study}

Table 1 shows the optimal sitting and sizing of capacitor banks using the POP at the normal condition for different loading conditions, at $150 \%$ and $200 \%$ of load demand, for the first real case study. From this Table, the optimal sitting of capacitor bank is at node No. 14 which the RDS has minimum values of total active power loss, total reactive power loss and total energy loss as well as maximum voltage regulation factor compared to the state which hasn't a capacitor bank. At the normal condition, the node No. 14 has the following properties:

Saving in $\mathrm{kW}=3.002 \mathrm{~kW}$,

Saving in $\mathrm{kWh}=19253.9 \mathrm{kWh}$,
Annual saving in $\mathrm{kW}=180.12 \mathrm{LE}$,

Annual saving in $\mathrm{kWh}=2695.546 \mathrm{LE}$,

Total annual saving $=2875.666 \mathrm{LE}$

However, the cost of capacitor bank will come back in 3.825 year

Table 2 shows the voltage performance index $(V R I)$ and the load performance index $(L P I)$ at each node of the feeder at the normal condition. In this Table, the node No. 14 has a minimum LPI or has the largest loading condition, which needs a capacitor bank to improve the performance of that node. These results confirm the POP results which is introduced in this study. To insure the OPP results, another sittings of the capacitor bank are carried out. However, Figures 5-9 show a comparison between the power factor, the total active power loss, the total reactive power loss, the total energy loss and the percentage of regulation factor for different sittings of the capacitor bank at different loading conditions. From these figures the optimal sitting of the capacitor bank is at node No. 14 at different loading conditions compared to other sitting of that capacitor.

Table 1. Optimal sitting and sizing of capacitor banks for the first case study

\begin{tabular}{|c|c|c|c|c|c|c|}
\hline & \multicolumn{2}{|c|}{ Actual Load } & \multicolumn{2}{|c|}{$150 \%$ Load } & \multicolumn{2}{|c|}{$200 \%$ Load } \\
\hline & $\begin{array}{l}\text { without } \\
\text { capacitor }\end{array}$ & $\begin{array}{c}\text { with } \\
\text { capacitor }\end{array}$ & $\begin{array}{l}\text { without } \\
\text { capacitor }\end{array}$ & $\begin{array}{c}\text { with } \\
\text { capacitor }\end{array}$ & $\begin{array}{l}\text { without } \\
\text { capacitor }\end{array}$ & $\begin{array}{c}\text { with } \\
\text { capacitor }\end{array}$ \\
\hline Node No. & - & 14 & - & 14 & - & 14 \\
\hline $\begin{array}{c}\text { No. of capacitor bank } \\
\text { units }\end{array}$ & - & 1 & - & 1 & - & 1 \\
\hline $\begin{array}{l}\text { Power factor at point } \\
14\end{array}$ & 0.82 & 0.92 & 0.82 & 0.87 & 0.82 & 0.87 \\
\hline $\begin{array}{l}\text { Total feeder current } \\
\text { (A) }\end{array}$ & 80 & 72 & 146 & 137 & 168 & 158 \\
\hline $\begin{array}{c}\text { Total active power } \\
\text { loss }(\mathrm{kW})\end{array}$ & 11.736 & 8.734 & 39.28 & 32.96 & 51.649 & 44.48 \\
\hline $\begin{array}{l}\text { Total reactive power } \\
\text { loss (kVAr) }\end{array}$ & 7.287 & 5.3894 & 24.367 & 20.39 & 31.982 & 27.72 \\
\hline $\begin{array}{c}\text { Total energy loss } \\
(\mathrm{kWh})\end{array}$ & 75266.9 & 56013 & 251888.4 & 211380.6 & 331238.6 & 287137.4 \\
\hline $\begin{array}{l}\text { Voltage regulation } \\
\text { factor } \%\end{array}$ & 7.682 & 7.5 & 8.557 & 8.371 & 8.834 & 8.646 \\
\hline
\end{tabular}

"-" denotes no capacitor banks.

Table 2. Performance regulation voltage and loading performance indices for the first case study

\begin{tabular}{|c|c|c|c|c|c|c|c|c|}
\hline $\begin{array}{c}\text { Node } \\
\text { No. }\end{array}$ & VRI\% & LPI\% & $\begin{array}{c}\text { Node } \\
\text { No. }\end{array}$ & VRI\% & LPI\% & $\begin{array}{c}\text { Node } \\
\text { No. }\end{array}$ & VRI\% & LPI\% \\
\hline 1 & 6.636 & - & 6 & 7.327 & - & 11 & 7.389 & 99.38 \\
\hline 2 & 6.655 & - & 7 & 7.359 & 98.45 & 12 & 7.552 & - \\
\hline 3 & 6.948 & - & 8 & 7.361 & 92.35 & 13 & 7.588 & 81.49 \\
\hline 4 & 7.107 & - & 9 & 7.387 & 88.89 & 14 & 7.668 & 67.92 \\
\hline 5 & 7.11 & 92.1 & 10 & 7.388 & 99.15 & 15 & 7.682 & 80.26 \\
\hline
\end{tabular}

"." denotes that no load demand at this node. 


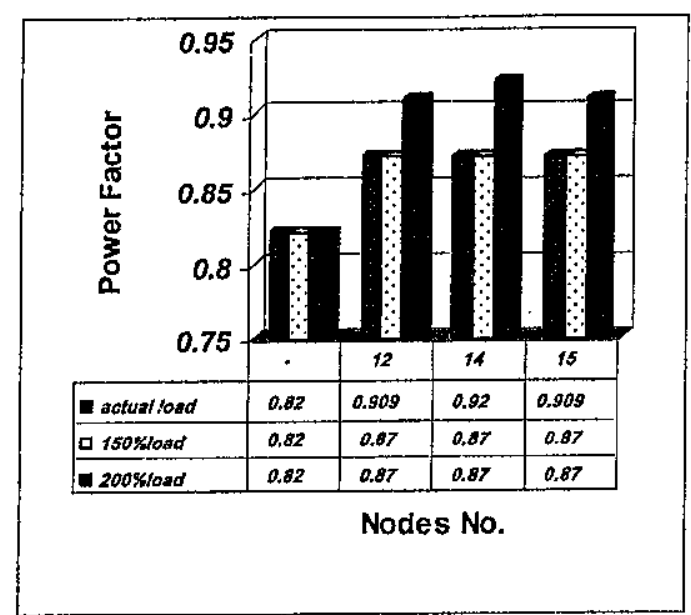

Fig. 5. A comparison between the power factor for different sittings of capacitor bank at different loading conditions

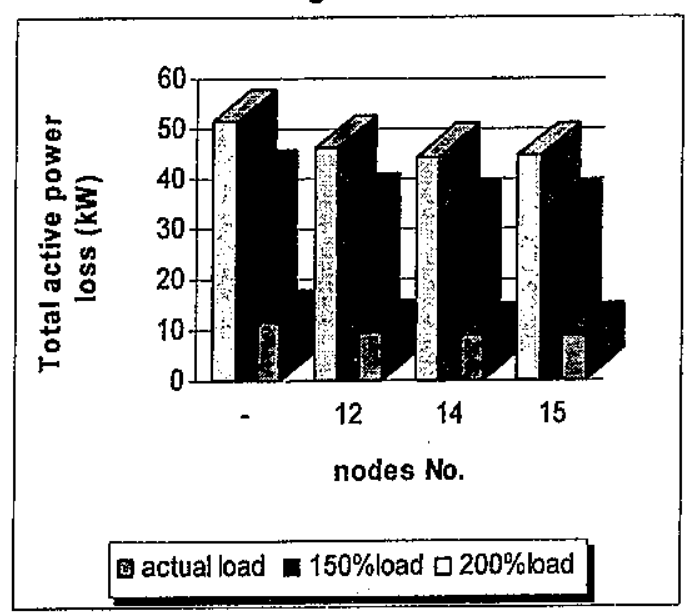

Fig. 6. A comparison between total active power loss for different sittings of capacitor bank at different loading conditions

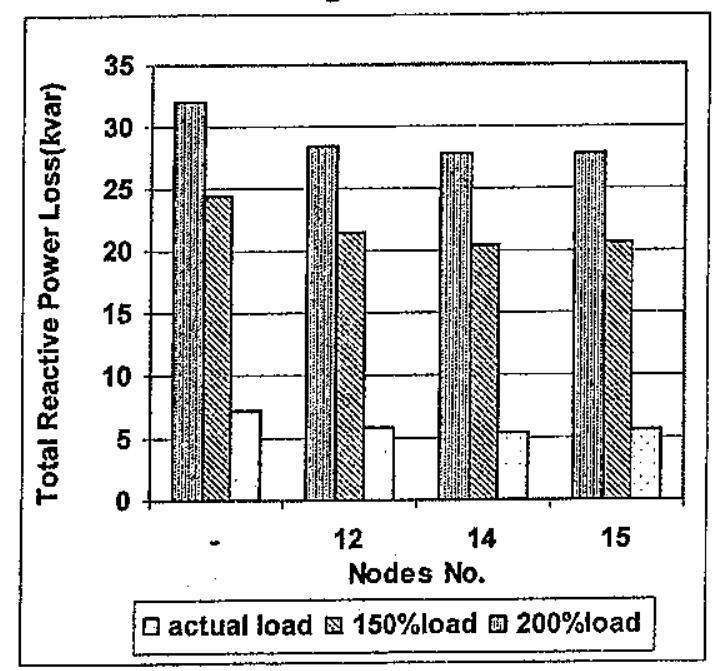

Fig. 7. A comparison between total reactive power loss for different sittings of capacitor bank at different loading conditions

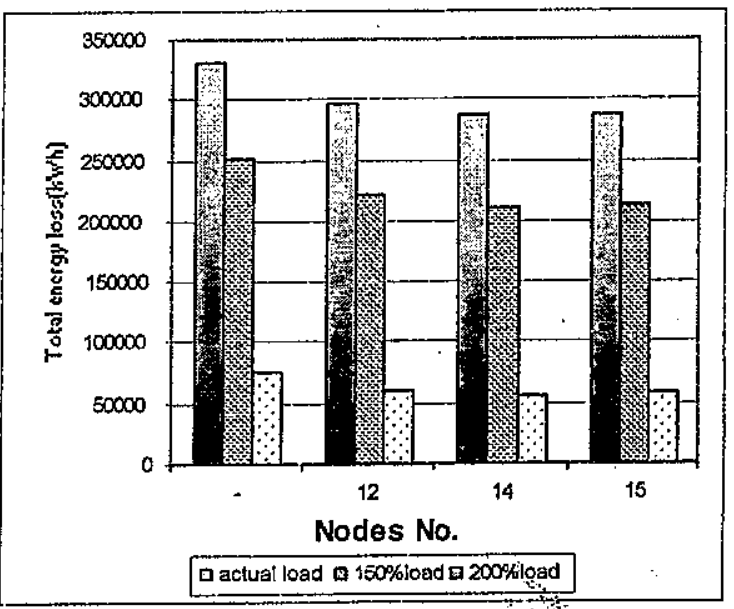

Fig. 8. A comparison between total energy loss for different sittings of capacitor bank at different loading conditions

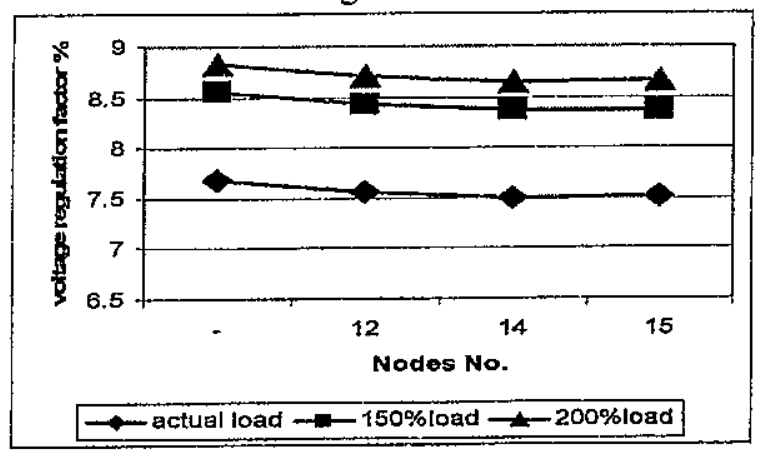

Fig. 9 A comparison between voltage regulation factor for different sittings of capacitor bank at different loading conditions

\subsubsection{Second case study}

Table 3 shows the optimal sitting and sizing of capacitor banks using the POP at the normal condition for loading conditions, at $150 \%$ and $200 \%$ of load demand, for the second case study. From this Table, the optimal sitting of capacitor banks are at nodes 26 and 60 which the RDS has minimum values of total active power loss, total reactive power loss and total energy loss as well as maximum voltage regulation compared to the state which hasn't a capacitor bank. At normal condition, the nodes 26 and 60 have the following properties:

Saving in $\mathrm{kW}=62.317 \mathrm{~kW}$

Saving in $\mathrm{kWh}=343973 \mathrm{kWh}$

Annual saving in $\mathrm{kW}=3739.02 \mathrm{LE}$

Annual saving in $\mathrm{kWh}=48156.22 \mathrm{LE}$

Total annual saving $=51895.24 \mathrm{LE}$

However, the cost of capacitor banks will come back in 0.64 year

Table 4 shows the voltage performance index $(V R I)$ and the load performance index (LPI) at each node of the feeder at normal condition. In this Table, the nodes 26 and 60 has a minimum $L P I$ or has the 
largest loading condition, which need a capacitor banks to improve the performance of that nodes. These results confirm the POP results which is introduced in this study. To insure the POP results, another sittings of the capacitor banks are carried out. However, Figures 10-14 show a comparison between the power factor, the total active power loss, the total reactive power loss, the total energy loss and the percentage of regulation factor for different sittings of the capacitor bank at different loading conditions. From these figures the optimal sitting of the capacitor banks are at nodes 26 and 60 at different loading conditions compared to other sitting of that capacitors.

Table 3. Optimal sitting and sizing of capacitor banks for the second case study

\begin{tabular}{|l|c|c|c|c|c|c|}
\hline & \multicolumn{2}{|c|}{ Actual Load } & \multicolumn{2}{|c|}{$150 \%$ Load } & \multicolumn{2}{|c|}{$200 \%$ Load } \\
\hline & $\begin{array}{c}\text { without } \\
\text { capacitor }\end{array}$ & $\begin{array}{c}\text { with } \\
\text { capacitor }\end{array}$ & $\begin{array}{c}\text { without } \\
\text { capacitor }\end{array}$ & $\begin{array}{c}\text { with } \\
\text { capacitor }\end{array}$ & $\begin{array}{c}\text { without } \\
\text { capacitor }\end{array}$ & $\begin{array}{c}\text { with } \\
\text { capacitor }\end{array}$ \\
\hline Node No. & - & 26,60 & - & 26,60 & - & 26,60 \\
\hline No. of capacitor bank units & - & 1,2 & - & 1,2 & - & 1,2 \\
\hline power factor at point 14 & 0.9 & 0.97 & 0.87 & 0.94 & 0.86 & 0.94 \\
\hline Total feeder current (A) & 200 & 176 & 270 & 239 & 280 & 248 \\
\hline Total active power loss (kW) & 304.375 & 242.058 & 524.466 & 420.234 & 555.438 & 445.793 \\
\hline Total reactive potver loss (kVAr) & 362.222 & 285.522 & 635.192 & 506.053 & 676.788 & 540.126 \\
\hline Total energy loss (kWh) & 1680053 & 1336080 & 2894882 & 2319557 & 3065837 & 2460631 \\
\hline Voltage regulation factor\% & 18.246 & 14.049 & 23.69 & 18.956 & 24.298 & 19.497 \\
\hline
\end{tabular}

Table 4. Performance voltage and performance loading indices for each node of the feeder

\begin{tabular}{|c|c|c|c|c|c|c|c|c|}
\hline Node No. & VRI\% & LPI\% & Node No. & VRI\% & LPI\% & Node No. & VRI\% & LPI\% \\
\hline$I$ & 2.5 & - & 23 & 13.59 & 95.76 & 45 & 16.544 & 99.79 \\
\hline 2 & 2.676 & $=$ & 24 & 14.473 & - & 46 & 16.544 & 99.43 \\
\hline 3 & 5.983 & - & 25 & 14.512 & 97.64 & 47 & 16.545 & 99.43 \\
\hline 4 & 6.042 & - & 26 & 14.533 & 95.38 & 48 & 16.55 & 99.64 \\
\hline 5 & 9.141 & - & 27 & 15.454 & - & 49 & 17.253 & - \\
\hline 6 & 9.440 & 97.39 & 28 & 15.748 & - & 50 & 17.289 & 96.72 \\
\hline 7 & 10.039 & 96.47 & 29 & 15.756 & 97.64 & 51 & 17.273 & 96.87 \\
\hline 8 & 10.116 & - & 30 & 15.799 & - & 52 & 17.622 & - \\
\hline 9 & 10.125 & 97.64 & 31 & 15.816 & 96.09 & 53 & 17.693 & - \\
\hline 10 & 10.861 & - & 32 & 15.888 & 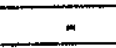 & 54 & 17.704 & 96.53 \\
\hline 11 & 10.884 & - & 33 & 15.925 & - & 55 & 17.744 & 95.95 \\
\hline 12 & 10.888 & 95.58 & 34 & 15.906 & 95.45 & 56 & 17.789 & 95.95 \\
\hline 13 & 10.945 & 96.42 & 35 & 15.908 & 98.12 & 57 & 17.903 & 97.55 \\
\hline 14 & 12.129 & - & 36 & 15.916 & 98.61 & 58 & 18.116 & - \\
\hline 15 & 12.172 & - & 37 & 15.926 & 98.47 & 59 & 18.141 & $=$ \\
\hline 16 & 12.176 & 98.77 & 38 & 16.001 & - & 60 & 18.171 & 94.13 \\
\hline 17 & 12.175 & 98.82 & 39 & 16.072 & 97.03 & 61 & 18.151 & 98.75 \\
\hline 18 & 12.212 & 98.66 & 40 & 16.048 & 95.85 & 62 & 18.165 & 97.72 \\
\hline 19 & 12.44 & $=$ & 41 & 16.066 & 96.75 & 63 & 18.196 & - \\
\hline 20 & 12.446 & 97.88 & 42 & 16,522 & - & 64 & 18.202 & 96.84 \\
\hline 21 & 13.552 & - & 43 & 16.543 & - & 65 & 18.241 & 96.75 \\
\hline 22 & 13.574 & 97.88 & 44 & 16.544 & - & 66 & 18.246 & 96.59 \\
\hline
\end{tabular}


Adel A. Abou El-Ela, Gamal E. M. Aly, and Abeer A. E. Shammah, "Optimal Sitting and Sizing of ......"

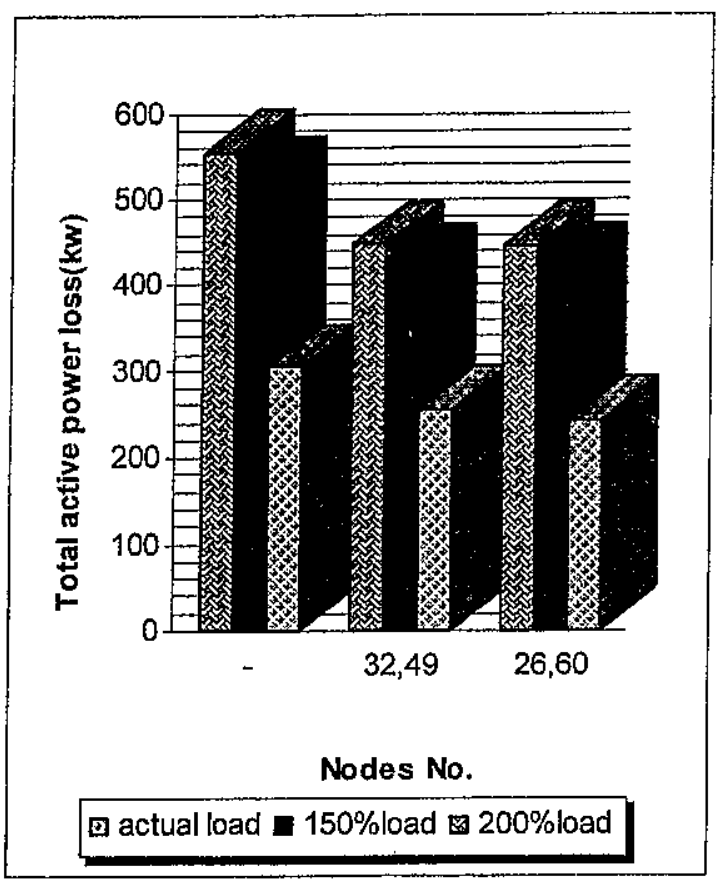

Fig. 10. A comparison between the power factor for different sittings of capacitor bank at different loading conditions

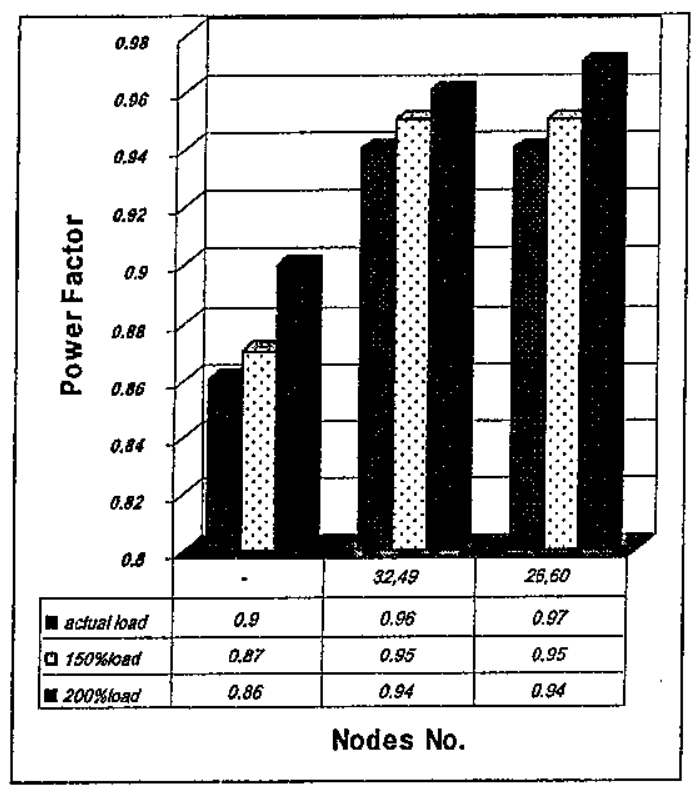

Fig. 11. A comparison between voltage regulation factor for different sittings of capacitor bank at different loading conditions

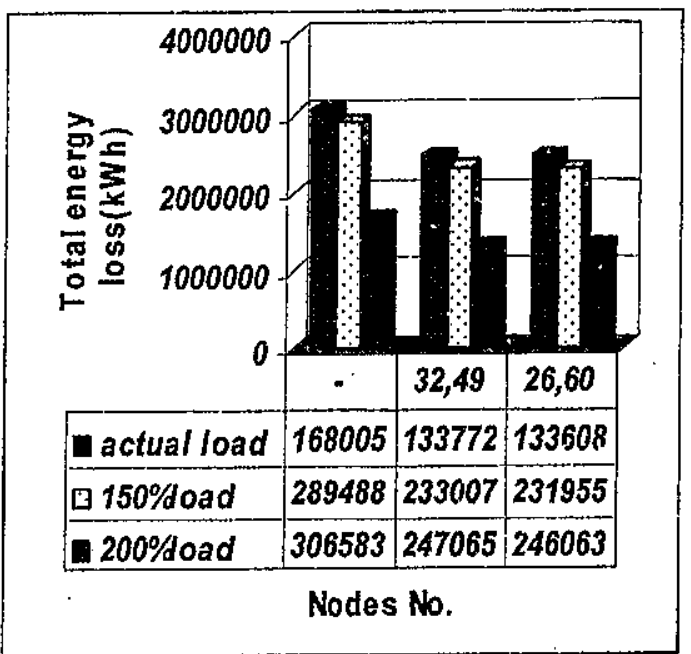

Fig. 12. A comparison between total reactive power loss for different sittings of capacitor bank at different loading conditions

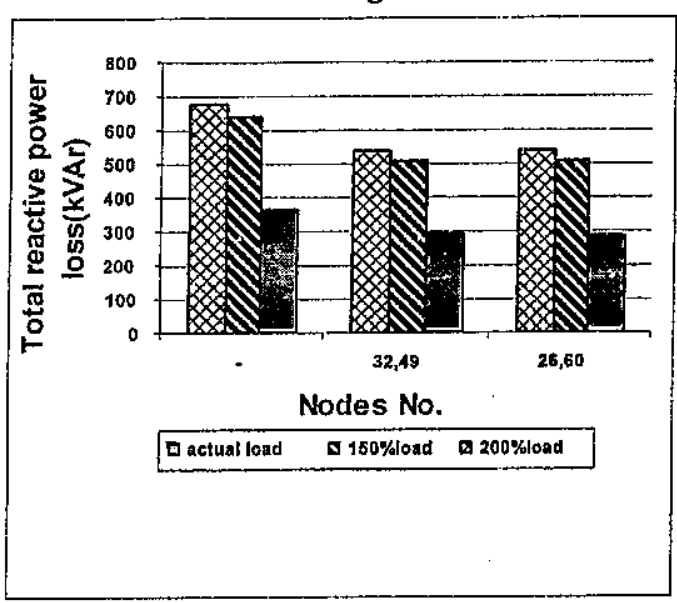

Fig. 13. A comparison between total energy loss for different sittings of capacitor bank at different loading conditions

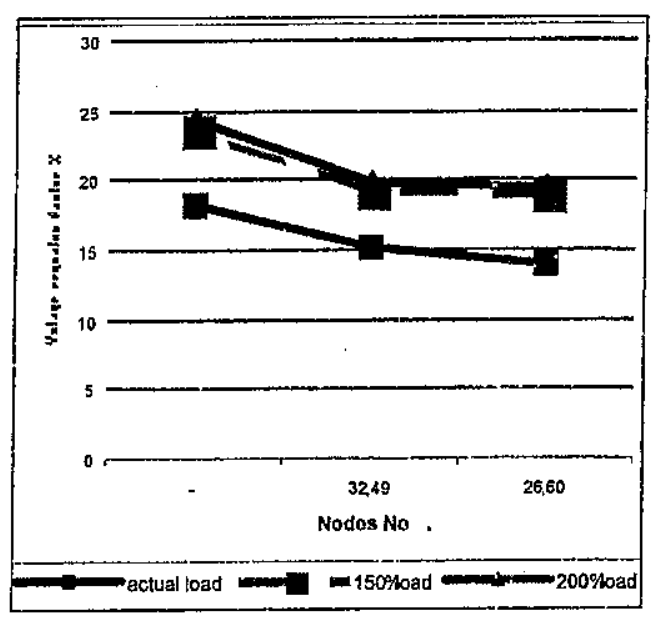

Fig. 14. A comparison between voltage regulation factor for different sittings of capacitor bank at different loading conditions 


\section{CONCLUSIONS}

An efficient proposed optimization procedure (POP) for planning and operation of distribution systems has been introduced. This procedure has been efficiently applied to find the optimal sitting and sizing of capacitor banks in order to achieve multiobjective functions which minimizes the active power losses and energy losses cost as well as minimizes the voltage deviations with respect to the flat voltage (11 $\mathrm{kV})$. The POP has been successfully applied to choose the optimal sitting and sizing of the capacitor banks which are suitable for existing and expansion load demand while the distribution system constraints are satisfied.

The voltage regulation index and the loading performance index the system operators to defined the critical nodes the RDS which need to installed one or more capacitor banks to improve the performance of that system.

\section{REFERENCES}

[1] J. J. Grainger and S. H. Lee, "Capacity Release by Shunt Capacitor Placement on Distribution Feeders: A New Voltage - Dependent Model", IEEE Transactions on Power Apparatus and systems, Vol.. PAS-101, No. 15, pp. 1236 1244, May 1982.

[2] J. J. Grainger and S. Civanlar, "Volt/VAR Control on Distribution Systems with Lateral Branches using Shunt Capacitors and Voltage Regulators", Part I, $\Pi$ and III. IEEE Transactions on Power Apparatus and systems, Vol. PAS104, No.11, pp. 3278 - 3297, Nov. 1985.

[3] F. Li, J. D. Pilgrim, C. Dabeedin, A. Chebbo, and R. K. Aggarwal., "Genetic Algorithms for Optimal Reactive Power Compensation on the National Grid Systems", IEEE Transactions on Power Systems, Vol. 20, No.1, pp. 493 - 500, Feb. 2005.
[4] A. Hossam El-din, A. R. Abdelaziz, IEEE senior members and W. M. Mokhtar, "Optimal Capacitor Placement in Distribution Systems by Genetic Algorithm", MEPCON, pp. 231-238, Dec. 16-18, 2003.

[5] M. M. Abouelsaad, M. Abd-elsalam, I. M. Elshair and K. I. Mohamed, "A genetic Algorithm for Optimal Placement of Fixed Capacitors on Radial Distribution Systems", MEPCON, pp. 235-259, Dec. 16-18, 2003.

[6] T. Ghose, S. Basu., "Soiving Capacitor Placement Problems in Distribution Systems using Genetic Algorithms", International Journal of Electrical Power and Energy systems, Vol. 27, pp. 429- 444, 1999.

[7] Y. C. Huang, H. T. Yang, and C. L. Huang, "Solving the Capacitor Placement Problem in A radial Distribution System using Tabu Search Approach", IEEE Transactions on Power systems, Vol. 4, pp.1868 - 1873, 1996.

[8] M. Chis, M. M. A. Salama and S. Jayaram, "Capacitor Placement in Distribution Systems using Heuristic Search Strategies", IEE Proceedings on Generation, Transmission and Distribution, Vol. 144, No. 3, pp. $225-230$, 1997.

[9] T. Saric, M. S. Calovicand M. B. Djukanovic., "Fuzzy Optimization of Capacitors in Distribution Systems", IEE Proceedings on Generation, Transmission and Distribution, Vol. 144, No. 5, pp. $415-422$, 1997.

[10]A. Abou El-Ela, G. E. M. Aly and A. A. E. Shammah, "Multi-Objective Optimal Planning and Operation of Distribution Systems using Genetic Algorithm," International Energy Journal 8, pp. 291-300, 2007.

[11]A. E. Shammah, "Optimal Control Actions of Distribution Networks using Artificial intelligence Techniques", M. Sc. thesis, Tanta University, Faculty of Engineering, 2008. 